\title{
Annual spatio-temporal migration patterns of Hooded Cranes wintering in Izumi based on satellite tracking and their implications for conservation
}

\author{
Chunrong $\mathrm{Mi}^{1}$, Anders Pape Møller ${ }^{2}$ and Yumin Guo ${ }^{1 *}$ (1)
}

\begin{abstract}
Background: The Hooded Crane (Grus monacha) is listed as a vulnerable species by IUCN. Knowledge about the migration of the Hooded Crane is still limited. Here we reported the spatio-temporal migration patterns of Hooded Cranes wintering in Izumi, Japan, as well as important stopover areas for their conservation.

Methods: Four adult and five subadult cranes, all wintering in Izumi, Japan, were fitted with satellite transmitters (GPS-GSM system) at their stopover sites in northeastern China in 2014 and 2015. We analyzed the time and duration of adults and subadults in spring and autumn migration, as well as the time and duration they stayed in breeding and wintering ground. In addition, we analyzed the land use of the cranes in stopover areas.

Results: Adult cranes took much longer time to migrate both north in spring (mean $=44.3$ days) and south in fall (mean $=54.0$ days) compared with subadult cranes (15.3 and 5.2 days, respectively). However, the subadults had longer wintering (mean $=149.8$ days) and nomadic (breeding season for adults) seasons (mean $=196.8$ days) compared with adults (133.8 and 122.3 days, respectively). Three important stopover areas have been identified: the region around Muraviovka Park in Russia, the Songnen Plain in China, and the west coast of South Korea, where cranes spent most of their migration time (62.2 and $85.7 \%$ in spring and autumn, respectively). During migration, nomadic period and winter, Hooded Cranes usually stay in croplands for resting and feeding. In non-wintering season, less than $6 \%$ of stopover sites were located within protected areas.
\end{abstract}

Conclusion: Overall, our results contribute to understanding the annual spatio-temporal migration patterns of Hooded Cranes in the eastern flyway, and planning conservation measures for this species.

Keywords: Conservation, Eastern migration route, Hooded Cranes (Grus monacha), Izumi, Satellite tracking, Spatiotemporal migration patterns

\section{Background}

Tracking birds and identifying their important habitats over large spatial scales is technically difficult. In the early 1990s, it became possible to track the full annual migrations of individual birds (Jouventin and Weimerskirch 1990; Berthold et al. 1992; Meyburg et al. 1995;

\footnotetext{
${ }^{*}$ Correspondence: guoyumin@bjfu.edu.cn

${ }^{1}$ College of Nature Conservation, Beijing Forestry University, Beijing 100083, China

Full list of author information is available at the end of the article
}

Kjellén and Alerstam 1997; Gschweng et al. 2012). Since then, an increasing number of studies including the year-round tracks of individual birds had been reported. This has resulted in important new knowledge about within- and among-individual variation in the temporal and spatial patterns of migration (Battley 2006; Hooijmeijer et al. 2014).

Satellite-tracking has become a useful means for tracking the migration of medium and large-sized birds such as cranes (Higuchi 1996; Higuchi et al. 2002; Qian et al. 2009), waterfowl (Lorentsen et al. 1998; Javed et al. 
2000) and storks (Berthold et al. 1992). This technique facilitates the determination of the location and migration distance, duration and speed (Robert et al. 2009; Minton et al. 2010; Klaassen et al. 2011) over medium and large scales and assessment of habitat characteristics at those scales (e.g., Fancy et al. 1988). The main advantages of this technique are the large spatial scales over which they can be employed and the fact that data can be collected from remote locations (Higuchi et al. 2004).

The Hooded Crane (Grus monacha) is a vulnerable (VU) species according to the IUCN Red List (IUCN 2016). The estimated world population of this species is 11,600 individuals (IUCN 2016). Hooded Cranes breed in Russian Far East and northeast China (Li 1993; Liu et al. 2001; Guo et al. 2005), and winter in southern Japan, southern Korea, and the Yangtze River basin of China (Harris et al. 2000; IUCN 2016). The population that winters in China is estimated to consist of 1050-1150 individuals, and there are approximately 10,500 individuals wintering in Japan (IUCN 2016).

Past studies of Hooded Cranes have mainly focused on their behavioral ecology, such as food habits at stopover sites (Huang and Guo 2015; Zhao et al. 2002), activity budgets in winter and breeding season (Zhou et al. 2016a, b; Xu et al. 2006), and habitat selection (Zhang et al. 2011; Zhao et al. 2013; Cai et al. 2014). In addition, some research assessed the population size and trends, threat and conservation actions for the Hooded Crane (Meine and Archibald 1996; Li et al. 2012; Harris and Mirande 2013). Although research has been conducted on other cranes distributed in East Asia, e.g. White-naped Crane (Grus vipio; Higuchi 1996; Higuchi et al. 2004), Redcrowned Crane (G. japonensis; Higuchi et al. 2002), Black-necked Crane (G. nigricollis; Qian et al. 2009), Demoiselle Crane (G. virgo; Guo and He 2017) and Siberian Crane (G. leucogeranus; Li et al. 2016), there is little knowledge about Hooded Cranes' migration ecology, like accurate migration time and duration, stopover sites. The purpose of this study was to fill the gap of knowledge of migration of the Hooded Crane: to describe the pathway and pattern of Hooded Crane migration, to identify the sites that are important for conservation and to assess the effect of protected areas for this species.

\section{Methods}

\section{Field work}

From 2014 to 2016, 16 Hooded Cranes were fitted with satellite transmitters in northeastern China and southern Russia, of which 9 wintered in Izumi, Japan (Table 1), and 7 wintered in China. We examined the movements of nine satellite-tagged Hooded Cranes that wintered in Izumi. All the 16 individuals were captured at stopover sites in the Songnen Plain of northeast China, using a pole trap or a mist net in combination with a stuffed raptor. The birds were released within $10 \mathrm{~min}$ after capture. Transmitters were attached using a $7 \mathrm{~mm}$-carbon fiber ribbon harnesses that was made in Germany. We used a 22-g solar satellite tracking device (HQBP3622 backpack series, Hunan Global Messenger Technology Co., Ltd, Changsha, China). The transmitters were programmed to alternate between on and off every hour. Each transmitter had an individual number (ID). In addition to the tracking device, color rings were attached to the leg of each crane.

\section{Data processing}

Data were received via the GSM system (CMCC, China), with information of date, time, longitude, latitude, speed, aspect, altitude, temperature and battery voltage. The total tracking dataset from 2014 to 2016 for the nine individuals contained 84,276 fixes. For every track, the best signal, based on "location class", was categorized into five levels: A $( \pm 5 \mathrm{~m}), \mathrm{B}( \pm 10 \mathrm{~m})$, $\mathrm{C}( \pm 20 \mathrm{~m}), \mathrm{D}( \pm 100 \mathrm{~m})$ and invalid. In this study, we only used locations categorized as $\mathrm{A}, \mathrm{B}$, and $\mathrm{C}$. The starting point of the autumn track was the last fix from the respective breeding area or pre-migratory stopover area (see below), and thus the endpoint of the autumn track was the first point from the first wintering area (Izumi). The starting point of the spring track was the last fix from the last wintering area. The endpoint of the spring track was the first fix from the respective breeding area. Stopover sites (sites at which there was no movement) were identified when the crane's speed was 0 , and fly points were identified when the speed was greater than $10 \mathrm{~km} / \mathrm{h}$. In total, we obtained 69,420 location records from stopover sites and 2244 locations while birds were flying. The data are reported as mean \pm SE.

Table 1 Information of tagged individual Hooded Cranes that wintered in Izumi, Japan

\begin{tabular}{lllc}
\hline ID & $\begin{array}{l}\text { Status } \\
\text { at capture }\end{array}$ & Tracking period & $\begin{array}{l}\text { Number } \\
\text { of locations }\end{array}$ \\
\hline HC1 & Adult & 7 Apr. 2014-18 Apr. 2016 & 8978 \\
HC2 & Adult & 7 Apr. 2014-18 Apr. 2016 & 10,440 \\
HC3 & Adult & 7 Apr. 2014-18 Apr. 2016 & 10,994 \\
HC6 & Subadult & 19 Oct. 2014-5 May 2016 & 12,326 \\
HC9 & Adult & 3 Apr. 2015-22 Apr. 2016 & 7981 \\
HC12 & Subadult & 15 Apr. 2015-28 Apr. 2016 & 8281 \\
HC14 & Subadult & 15 Apr. 2015-18 Apr. 2016 & 8501 \\
HC15 & Subadult & 20 Apr. 2015-11 May 2016 & 8926 \\
HC16 & Subadult & 27 Apr. 2015-18 Apr. 2016 & 7849 \\
\hline
\end{tabular}




\section{Results}

\section{Spring and autumn migration}

In the process of analyzing migration data, we found three important stopover areas for spring and autumn migration (Fig. 1), based on the distribution of record sites: the region around Muraviovka Park in Russia, the Songnen Plain in northeast China, and the west coast of South Korea.

It took approximately $44.3 \pm 4.0$ days (5 March-12 May) for adults to migrate from the wintering grounds in Izumi, to their breeding areas. During their northward migration, the average time spent at the three most important migration stopover areas was $27.5 \pm 5.3$ days. Subadult individuals spent $15.3 \pm 2.8$ days (22 March-19 April), followed by nomadism across large areas, including: the Greater Khingan Mountains, the Lesser Khingan Mountains, the Songnen Plain, Sanjiang Plain and Muraviovka Park.

For their fall migration from their breeding areas to Izumi, adult cranes spent nearly $54.0 \pm 4.1$ days $(26$ August-29 October) on autumn migration, including $47.0 \pm 4.9$ days at the three most important stopover

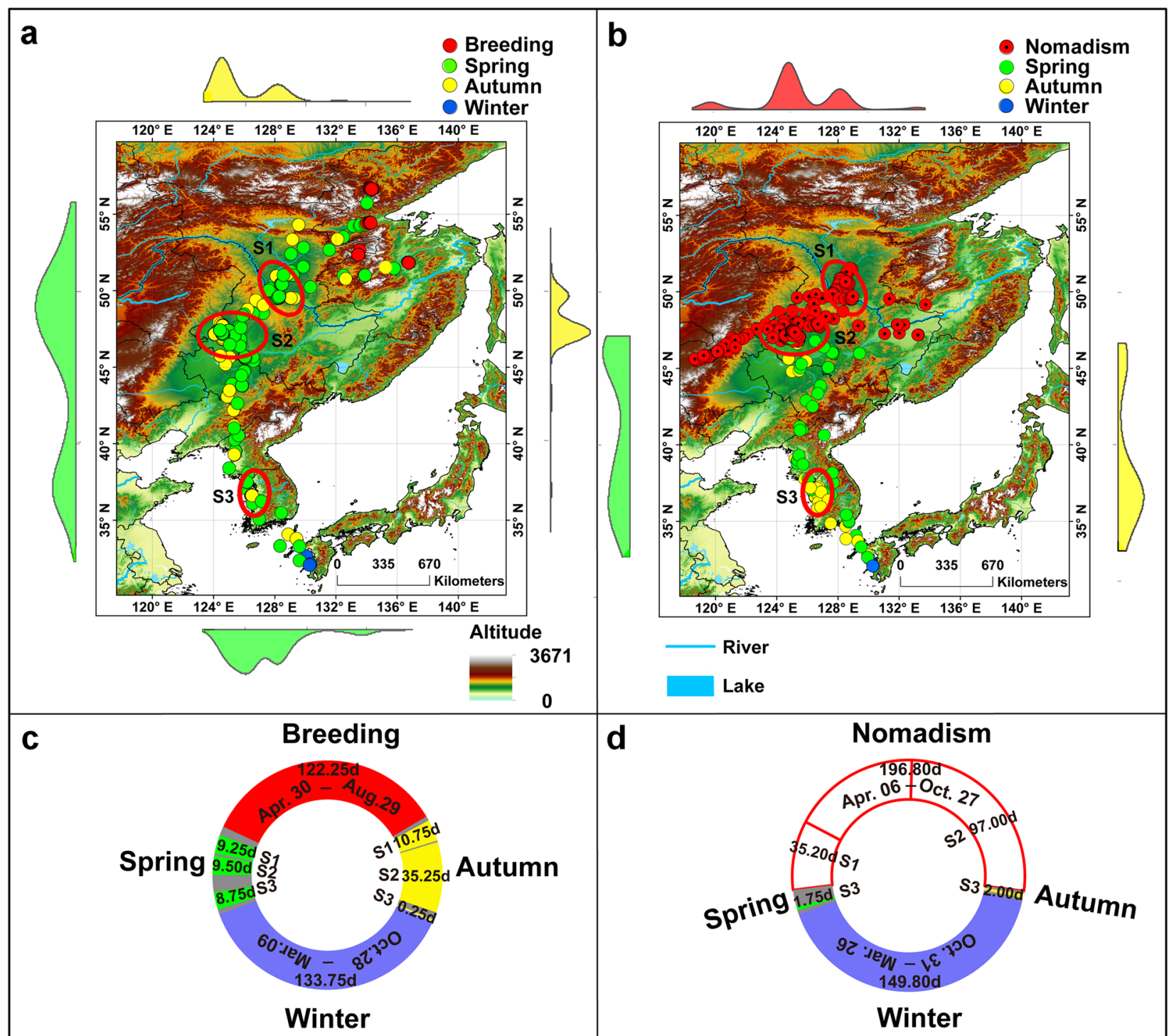

Fig. 1 Eastern migration route and spatio-temporal migration patterns of Hooded Cranes. The density figure shows the distribution of stopover and nomadism sites in relation to latitude and longitude. S1 represents the region around Muraviovka Park, S2 the region around Songnen Plain, and S3 the region along the west coast of South Korea. a Spatial migration pattern of adults, $\mathbf{b}$ spatial migration pattern of subadults, $\mathbf{c}$ temporal migration pattern of adults, and $\mathbf{d}$ temporal migration pattern of subadults 
sites (Muraviovka Park, Songnen Plain, and west coast of South Korea). Subadult individuals aggregated around Songnen Plain in September and then flew south at the end of October. They only spent $5.2 \pm 0.9$ days (23 October-29 October) on migration, including 2 days resting along the west coast of South Korea.

\section{Breeding and wintering}

The Hooded Cranes in this study all bred in Russia's Far East (Table 2). The individual HC1 bred near the basin of the Ulkan River in the center of Khabarovsk state, $\mathrm{HC} 2$ in Chukchagirskoye Lake in Khabarovsk state, HC3 in the wetland between Bokon Lake and the Maja River, and HC9 in the Akishm River, which forms the boundary between Khabarovsk state and Amur state. The duration of breeding period for adults was $122.3 \pm 6.0$ days, while that of nomadic period for subadults was $196.8 \pm 17.9$ days. The wintering periods for these two groups were $133.8 \pm 5.8$ and $149.8 \pm 0.5$ days, respectively.

\section{Land use}

Figure 2 shows the annual land use by Hooded Cranes at their stopover sites. During spring and autumn migration, Hooded Cranes consistently stayed in rainfed and mosaic cropland. At the wintering grounds in Izumi, they stayed in harvested rice cropland for the entire season. During breeding season, adult individuals laid and hatched their eggs in open coniferous forests, and nomadism of subadult individuals occurred over a large area with most of their time stopping and feeding in cropland as they did during migration.

\section{Conservation gap}

Hooded Cranes were found in protected areas over $43 \%$ of the time (30, 261/69, 420 fixes; Fig. 3; Table 3). In total, the Hooded Cranes stopped in 14 nature reserves, 6 in
Russia, 5 in China and 3 in Japan. Importantly, more than $86 \%$ of Hooded Crane locations in protected areas occurred in the Takaono Wildlife Protection Area, Izumi, Japan. In addition, Zhanglong, Changjigangshidi and Jingbohu in China, Amurskiy and the Zeya-Bureya Plains in Russia were the most important stopover sites for cranes during spring and autumn migration and for subadult nomadism. However, four breeding individuals ( $\mathrm{HC}$, $\mathrm{HC} 2, \mathrm{HC} 3$ and $\mathrm{HC} 9$ ) did not nest in nature reserves. Based on the temporal distribution of stopover sites, we found that all breeding sites occurred outside protected areas, while $93.6 \%$ of wintering sites were within protected areas in Izumi. During migration, only 18.6\% (spring) and 15.5\% (autumn) of the stopover sites were located in nature reserves. For subadult individuals, only $7.5 \%$ of the stopover sites were located in protected areas during the adult breeding season.

\section{Discussion}

In this study, the breeding grounds of Hooded Cranes were found to be in a remote area in Far East Russia (Fig. 1; Harris and Mirande 2013) with little human interference because of difficult accessibility. The wintering area in Izumi is a nature reserve and therefore, the Hooded Cranes are well protected. The most likely place and time that would cause a threat to cranes are stopover sites during migration (e.g. Hutto 1998; Klaassen et al. 2014), especially at sites where cranes stay for a long time. However, only 18.6 and $15.5 \%$ of the stopover sites were protected during spring and autumn migration (Table 4). On the migration route, three important migration stopover areas were identified (Muraviovka Park region, Songnen Plain and South Korea's west coast; see Fig. 1). These three areas were mainly covered with crops, such as corn, wheat and rice. It is likely that conflict would occur between humans and cranes for access to food. However, it can be challenging to designate

Table 2 Migration dates and breeding areas of Hooded Cranes ( $n=9$ cranes)

\begin{tabular}{|c|c|c|c|c|c|}
\hline ID & Status at capture & 2015 spring migration & 2015 autumn migration & 2016 spring migration & Breeding location \\
\hline $\mathrm{HC} 1$ & Adult & 24 Mar.-12 May & 26 Aug.-29 Oct. & 4 Mar. & The basin of Ulkan River \\
\hline $\mathrm{HC} 2$ & Adult & 5 Mar.-26 Apr. & 1 Sep.-29 Oct. & 26 Feb. & Chukchagirskoye Lake \\
\hline $\mathrm{HC} 3$ & Adult & 23 Mar.-4 May & 1 Sep.-29 Oct. & 21 Mar. & $\begin{array}{l}\text { The wetland between } \\
\text { Bokon Lake and Maja } \\
\text { River }\end{array}$ \\
\hline HC6 & Subadult & - & 24 Oct.-29 Oct. & 27 Mar. & - \\
\hline $\mathrm{HC} 9$ & Adult & To 18 Apr. & 29 Aug.-28 Oct. & 9 Mar. & The Akishm River \\
\hline $\mathrm{HC} 12$ & Subadult & - & 24 Oct.-29 Oct. & 26 Mar.-13 Apr. & - \\
\hline $\mathrm{HC} 14$ & Subadult & - & 24 Oct.-28 Oct. & 26 Mar.-29 Mar. & - \\
\hline $\mathrm{HC} 15$ & Subadult & - & 22 Oct.-1 Nov. & 28 Mar.-19 Apr. & - \\
\hline $\mathrm{HC} 16$ & Subadult & - & 23 Oct.-31 Oct. & 26 Mar.-11 Apr. & - \\
\hline
\end{tabular}

During July 2016 some cranes were flying out of China and only 2016 spring migration start dates were available 

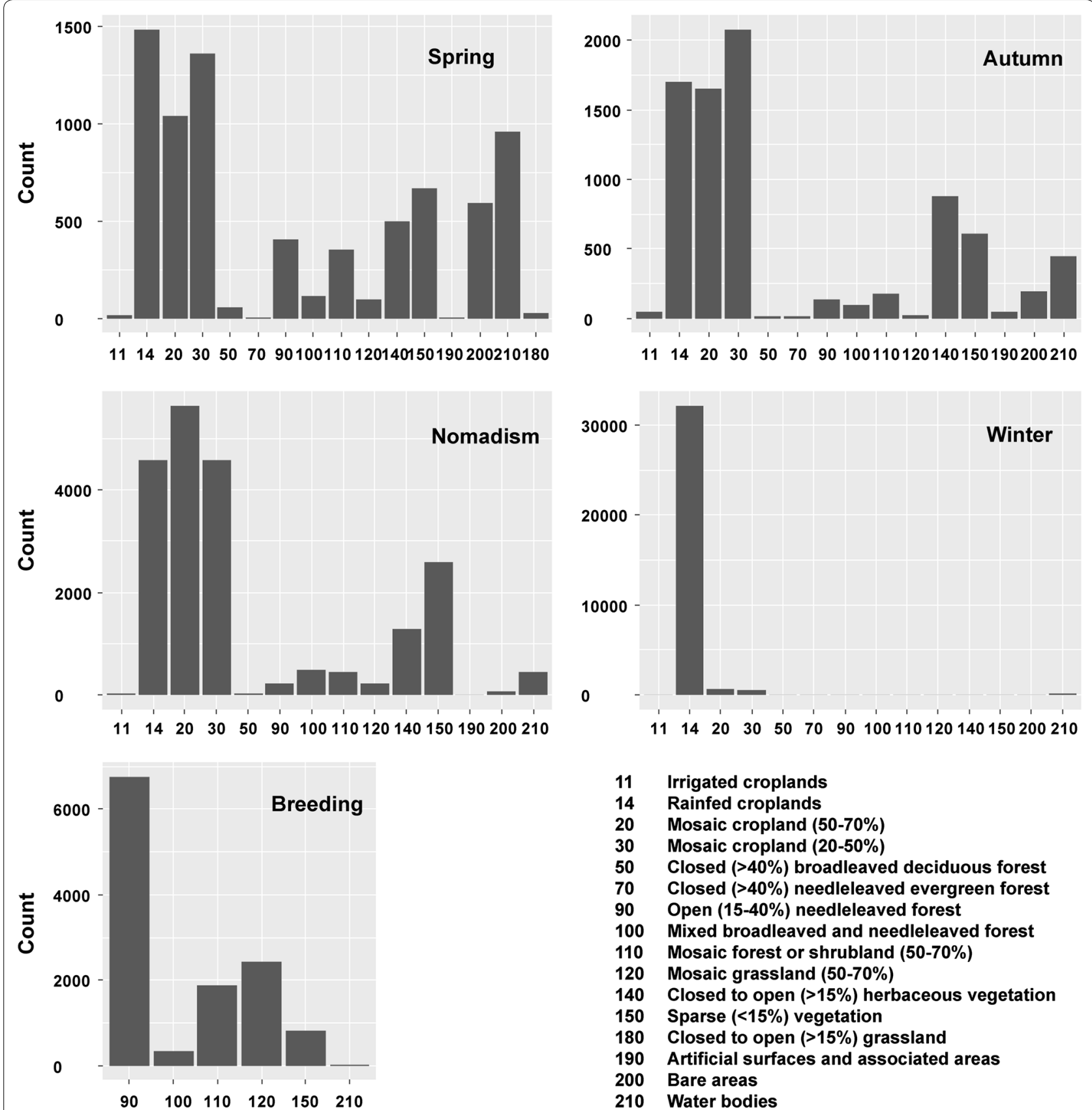

11 Irrigated croplands

14 Rainfed croplands

20 Mosaic cropland $(\mathbf{5 0 - 7 0 \% )}$

30 Mosaic cropland (20-50\%)

50 Closed $(>40 \%)$ broadleaved deciduous forest

70 Closed $(>40 \%)$ needleleaved evergreen forest

90 Open (15-40\%) needleleaved forest

100 Mixed broadleaved and needleleaved forest

110 Mosaic forest or shrubland $(\mathbf{5 0 - 7 0 \% )}$

120 Mosaic grassland $(50-70 \%)$

140 Closed to open (>15\%) herbaceous vegetation

150 Sparse $(<15 \%)$ vegetation

180 Closed to open (>15\%) grassland

190 Artificial surfaces and associated areas

200 Bare areas

210 Water bodies

Fig. 2 The annual land use of Hooded Cranes at stopover sites

nature reserves in agricultural land. Constructing seasonally protected areas may be a viable solution. Additional measures can be taken by local government such as strengthening the education of the local people on animal protection, organizing regular patrolling in these important sites during migration season, and providing financial compensations for farmers who suffered from economic losses because of the animals.
Based on satellite tracking data, we found that the behavior of nonbreeding individuals (subadults) and adults differed during the breeding season. They kept nomadic in the Greater Khingan Mountains, the Lesser Khingan Mountains, the Songnen Plain, the Sanjiang Plain and around Muraviovka Park after arriving at the Songnen Plain from Izumi. The subadults usually wandered in the region around Muraviovka Park 


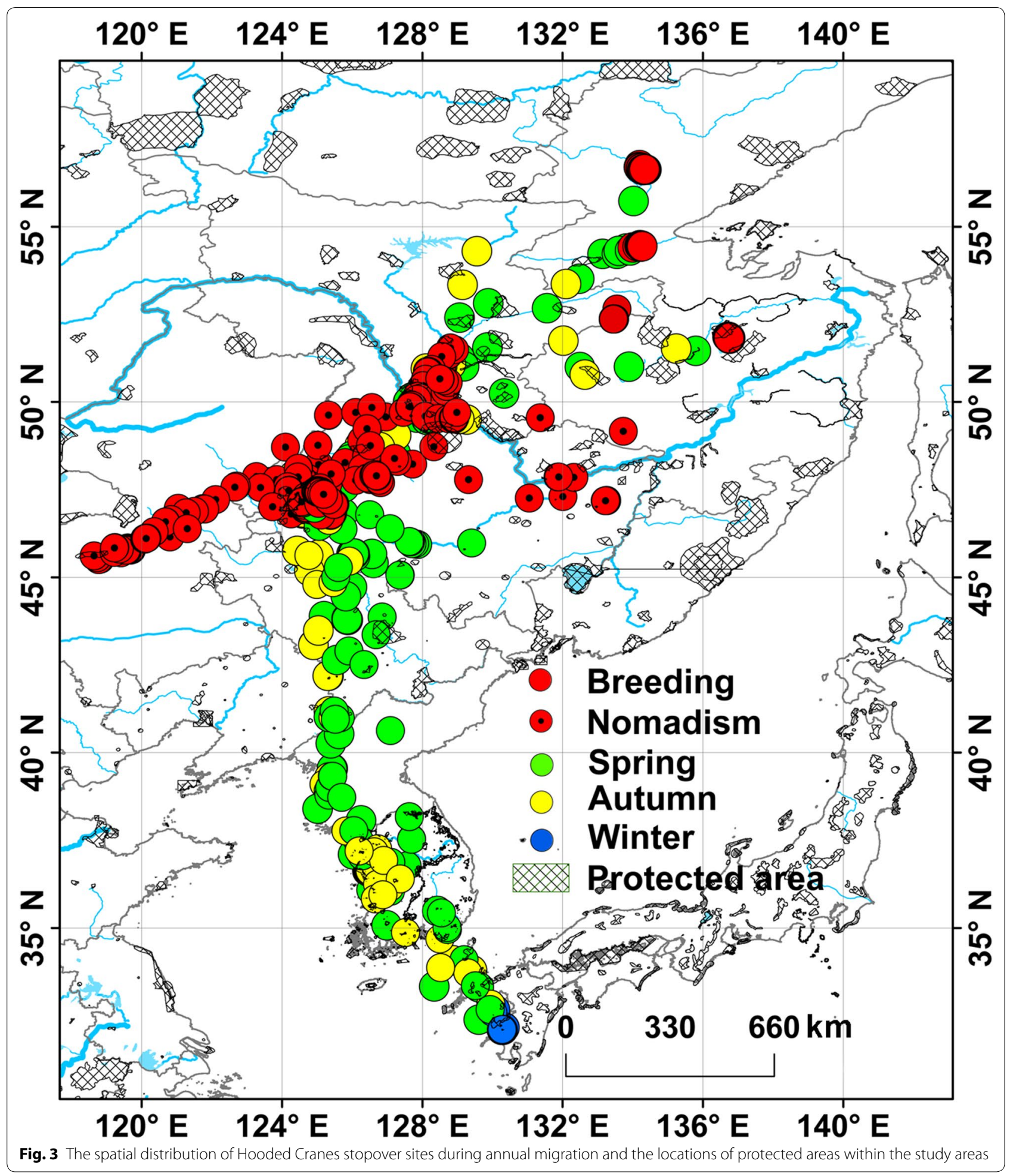

and Songnen Plain, and sometimes entered the breeding grounds in China. This could answer the question raised by Zheng (1987) regarding whether the individuals observed in the Sanjiang Plain and eastern Inner
Mongolia during summer were breeding. Non-breeding Hooded Cranes wintering in China also dispersed after their arrival at the Songnen Plain (Y. Guo, unpublished data). Thus, we argued that the Songnen Plain might 
Table 3 Spatial distribution of Hooded Crane stopover sites in protected areas ( $\boldsymbol{n}=\mathbf{9}$ cranes)

\begin{tabular}{|c|c|c|c|c|c|c|c|c|}
\hline Country & $\begin{array}{l}\text { Protected } \\
\text { area }\end{array}$ & $\begin{array}{l}\text { Longitude/ } \\
\text { latitude }\left({ }^{\circ}\right)\end{array}$ & Area $\left(\mathrm{km}^{2}\right)$ & $\begin{array}{l}\text { IUCN } \\
\text { category }\end{array}$ & $\begin{array}{l}\text { Number } \\
\text { of sites }\end{array}$ & Percent (\%) & Period & $\begin{array}{l}\text { Number } \\
\text { of individuals }\end{array}$ \\
\hline Russia & Vana & $132.63 / 54.01$ & 1059.57 & IV & 6 & 0.02 & Autumn & 2 \\
\hline Russia & Iverskiy & $128.65 / 51.76$ & 469.33 & IV & 1 & 0.00 & Nomadism & 1 \\
\hline Russia & Badzhal'sky & $127.69 / 49.96$ & 2873.51 & IV & 8 & 0.03 & Spring & 1 \\
\hline Russia & Murav'evskiy & $127.62 / 49.91$ & 357.03 & IV & 41 & 0.14 & $\begin{array}{l}\text { Spring, autumn, } \\
\text { nomadism }\end{array}$ & 4 \\
\hline Russia & Zeya-Bureya Plains & $127.68 / 49.85$ & 284.14 & Not reported & 512 & 1.69 & $\begin{array}{l}\text { Spring, autumn, } \\
\text { nomadism }\end{array}$ & 6 \\
\hline China & Ku'erbin & $128.32 / 48.72$ & 4845.39 & V & 14 & 0.05 & Spring & 1 \\
\hline China & Changjigangshidi & $124.16 / 47.47$ & 670.98 & V & 502 & 1.66 & $\begin{array}{l}\text { Nomadism, } \\
\text { autumn }\end{array}$ & 4 \\
\hline China & Zhalong & $124.54 / 47.15$ & 1264.69 & V & 1697 & 5.61 & $\begin{array}{l}\text { Spring, autumn, } \\
\text { nomadism }\end{array}$ & 8 \\
\hline China & Hesigechuor & $118.63 / 45.61$ & 1050.41 & V & 26 & 0.09 & Nomadism & 1 \\
\hline China & Jingbohu & $129.03 / 44.02$ & 1026.55 & V & 139 & 0.46 & Nomadism & 1 \\
\hline Japan & Iki-Tsushima & $129.29 / 34.26$ & 730.48 & V & 7 & 0.02 & $\begin{array}{l}\text { Nomadism, } \\
\text { autumn }\end{array}$ & 1 \\
\hline Japan & Saikai & $129.59 / 33.18$ & 703.09 & V & 6 & 0.02 & Spring & 1 \\
\hline \multirow[t]{2}{*}{ Japan } & Izumi-Takaono & $130.27 / 32.10$ & 8.16 & $\|$ & 26,219 & 86.64 & Winter & 9 \\
\hline & Total & & & & 30,261 & & & \\
\hline
\end{tabular}

IUCN Protected Area Categories System (https://www.iucn.org/theme/protected-areas/about/protected-area-categories)

II: national park; IV: habitat/species management area; V: protected landscape/seascape

Table 4 Temporal distribution of Hooded Crane stopover sites in protected areas

\begin{tabular}{llcc}
\hline Period & $\begin{array}{l}\text { Number } \\
\text { of locations }\end{array}$ & $\begin{array}{l}\text { Number of locations } \\
\text { in protected area }\end{array}$ & Percent (\%) \\
\hline Spring & 11,110 & 2065 & 18.59 \\
Breeding & 10,396 & 0 & 0.00 \\
Nomadism & 13,517 & 1012 & 7.49 \\
Autumn & 6424 & 994 & 15.47 \\
Winter & 27,973 & 26,190 & 93.63 \\
\hline
\end{tabular}

be the gathering site for eastern and western migrating subpopulations, and it is also an important stopover area or breeding area for other six crane species which distributes in Northeast Asia (White-naped Crane, Redcrowned Crane, Siberian Crane, Common Crane Grus grus, Demoiselle Crane, Sandhill Crane G. canadensis; Zou et al. 2018). However, cranes in the Songnen Plain are threatened by the habitat degradation and loss, as well as the use of pesticides in farmland, illegal hunting, transmission lines and wind farms (Lu et al. 2007; Mao et al. 2016; Zhou et al. 2016a, b; Zou et al. 2018).

Izumi was the most important wintering area for Hooded Cranes with over 10,500 individuals spending the winter there, although it only occupies $8.16 \mathrm{~km}^{2}$ (IUCN 2016). Artificial feeding is applied there to ensure that cranes can obtain sufficient food for wintering. However, this area is too small to accommodate so many birds, which makes it susceptible to the outbreak and transmission of avian influenza (Harris and Mirande 2013). This may lead to the death of a large number of individuals, and threaten the status and survival of this species (e.g., 4 individuals were sick or dying in Dec. 2010, and 18 died in Nov. 2016; http://afludiary.blogspot.com/).

One method that can be adopted to avoid this problem is to disperse the population to other suitable locations with human aids, although it would be difficult for cranes to move away from established locations. Suitable places should meet the following criteria: (1) located on the migration route; (2) containing sufficient food and water resources; (3) providing open, shallow water areas for nighttime roosting; and (4) with little human disturbance. Human intervention could be employed to resolve if one or a few conditions are not completely met. Contact calls and crane models could be used to lure cranes to stay in suitable locations. The primary area for the dispersal of the wintering population in Izumi may be the west coast of South Korea, if adequate food with open and fresh water could be provided. In the future, the Yellow River Delta which is at a similar latitude could also be considered as another suitable wintering area for the cranes. 


\section{Conclusions}

Our results contribute to the better understanding of Hooded Cranes' migration, providing information on the need for the protection of important sites, especially the Songnen Plain, which is a critical area. However, one limitation of our study was that only nine individuals with 2-year data were available. Nevertheless, our data are the best available, and our results provide information on both breeding and non-breeding individuals over the complete eastern migration cycle. Another limitation was that we only studied and described the eastern migration of Hooded Cranes. Future studies should focus on Hooded Cranes wintering further west, in the middle and lower basins of the Yangtze River in China.

\section{Authors' contributions}

YG conceived the study and collected the data, and CM prepared and analyzed the data and wrote the first draft of the manuscript. APM and YG helped with the writing of the text. All authors read and approved the final manuscript.

\section{Author details}

${ }^{1}$ College of Nature Conservation, Beijing Forestry University, Beijing 100083 , China. ${ }^{2}$ Ecologie Systématique Evolution, Université Paris-Sud, CNRS, AgroParisTech, Université Paris-Saclay, 91405 Orsay Cedex, France.

\section{Acknowledgements}

We are grateful to Mr. Jianguo Fu for his help in the fieldwork, and to Ms. Chuyu Cheng for her help with editing of this manuscript. Thanks also go to the State Forestry Administration and Whitley Fund for Nature (WFN).

\section{Competing interests}

The authors declare that they have no competing interests. The funders had no role in study design, data collection and analysis, decision to publish, or preparation of the manuscript.

\section{Consent for publication}

Not applicable.

\section{Ethical approval}

The investigations comply with the current laws of China in which they were performed.

\section{Funding}

This study was funded by the National Natural Science Foundation of China (Grant No. 31570532).

Received: 9 July 2017 Accepted: 18 June 2018

Published online: 12 July 2018

\section{References}

Battley P. Consistent annual schedules in a migratory shorebird. Biol Lett. 2006;2:517-20.

Berthold P, Nowak E, Querner U. Satellite tracking of White Storks during the autumn migratory period-a pilot study. J Ornithol. 1992;133:155-63.

Cai T, Hueetmann F, Guo Y. Using stochastic gradient boosting to infer stopover habitat selection and distribution of Hooded Cranes Grus monacha during spring migration in Lindian Northeast China. PLoS ONE. 2014;9:e89913.

Fancy S, Pank L, Douglas D, Curby C, Garner G, Amstrup S, Regelin W. Satellite telemetry: a new tool for wildlife research and management. Research Publication Number U.S. Fish and Wildlife Service. 1988. http://www.adfg. alaska.gov/static/home/library/pdfs/wildlife/research_pdfs/88_fancy _etal_satellite_telemetry_new_tool_wildlife_research_management.pdf. Accessed 25 Mar 2017.

Gschweng M, Elisabeth K, Berthold P, Fiedler W, Fahr J. Multi-temporal distribution modelling with satellite tracking data: predicting responses of a long-distance migrant to changing environmental conditions. J Appl Ecol. 2012:49:803-13.

Guo Y, He F. Preliminary results of satellite tracking on Ordos Demoiselle Cranes. Chin J Wild. 2017;38:141-3 (in Chinese).

Guo Y, Liu X, Xu C, Li L. A preliminary census of Hooded Crane population in the breeding area of Lesser Xingan Mountains. Chin J Zool. 2005;40:51-4 (in Chinese)

Harris J, Mirande C. A global overview of cranes: status threats and conservation priorities. J Biomech. 2013;4:189-209.

Harris J, Su L, Highchi H, Ueta M, Zhang Z, Zhang Y, Ni X. Migratory stopover and wintering locations in eastern China used by White-naped Cranes Grus vipio and Hooded Cranes G. monacha as determined by satellite tracking. Fork. 2000;16:93-9.

Higuchi H, Pierre J, Krever V, Andronov V, Fujita G, Ozaki K, Goroshko O, Ueta $\mathrm{M}$, Smirensky S, Mita N. Using a remote technology in conservation: satellite tracking White-naped Cranes in Russia and Asia. Conserv Biol. 2004;18:136-47.

Higuchi H, Shibaev Y, Minton J, Ozaki K, Surmach S, Fujita G, Momose K, Momose $Y$, Ueta M, Andronov V. Satellite tracking of the migration of the red-crowned crane Grus japonensis. Ecol Res. 2002;13:273-82.

Higuchi H. Satellite-tracking White-naped Crane Grus vipio migration and the importance of the Korean DMZ. Conserv Biol. 1996;10:806-12.

Hooijmeijer J, Gill R, Mulcahy D, Tibbitts T, Kentie R, Gerritsen G, Bruinzeel L, Tijssen D, Harwood C, Piersma T. Abdominally implanted satellite transmitters affect reproduction and survival rather than migration of large shorebirds. J Ornithol. 2014;155:1-11.

Huang J, Guo Y. Diet of Hooded Crane (Grus monacha) in autumn Lindian China. Chin J Wildl. 2015;36:76-9 (in Chinese)

Hutto R. Overviews on the importance of stopover sites to migrating birds. Auk. 1998;115:823-5.

IUCN. Grus monacha. The IUCN red list of threatened species. 2016. http:// www.iucnredlist.org/details/22692151/0. Accessed 1 Oct 2016.

Javed S, Takekawa J, Douglas D, Rahmani A, Kanai Y, Nagendran M, Choudhury $\mathrm{B}$, Sharma S. Tracking the spring migration of a Bar-headed goose (Anser indicus) across the Himalaya with satellite telemetry. Glob Environ Res. 2000;4:195-205.

Jouventin P, Weimerskirch $\mathrm{H}$. Satellite tracking of wandering albatrosses. Nature. 1990;343:746-8

Kjellén N, Alerstam T. Strategies of two ospreys Pandion haliaetus migrating between Sweden and tropical Africa as revealed by satellite tracking. J Avian Biol. 1997;28:15-23.

Klaassen R, Alerstam T, Carlsson P, Fox JW, Lindström A. Great flights by great snipes: long and fast non-stop migration over benign habitats. Biol Lett. 2011;7:833-5.

Klaassen R, Hake M, Strandberg R, Koks BJ, Trierweiler C, Exo K, Bairlein F, Alerstam T. When and where does mortality occur in migratory birds? Direct evidence from long-term satellite tracking of raptors. J Anim Ecol. 2014:83:176-84.

Li F, Wu J, Harris J, Burnham J. Number and distribution of cranes wintering at Poyang Lake China during 2011-2012. Chin Birds. 2012;3:180-90.

Li L. The first discovery of Hooded Crane breeding in China. Chin J Wildl. 1993:75:16 (in Chinese)

Li X, Xu J, Qian F. Migration routes of Siberian Crane (Grus leucogeranus) in spring and autumn by satellite tracking. Wetl Sci. 2016;14:347-53 (in Chinese)

Liu X, Zhao W, Liu X, Lan C, Zhou X, Guo Y. Breeding Hooded Crane is found in Zhanhe Forest in Heilongjiang Province. Chin Wildl. 2001;22:41 (in Chinese)

Lorentsen S, Øien I, Aarvak T. Migration of Fennoscandian lesser white-fronted geese Anser erythropus mapped by satellite telemetry. Biol Conserv. 1998;84:47-52

Lu H, Campbell D, Chen J, Qin P, Ren H. Conservation and economic viability of nature reserves: an energy evaluation of the Yancheng Biosphere Reserve. Biol Conserv. 2007;139:415-38. 
Mao D, Wang Z, Luo L, Ren C, Jia M. Monitoring the evolution of wetland ecosystem pattern in northeast China from 1990 to 2013 based on remote sensing. J Nat Resour. 2016;31:1253-63 (in Chinese).

Meine C, Archibald G. The cranes: status survey and conservation action plan IUCN. 1996. https://portals.iucn.org/library/efiles/documents/1996-022. pdf. Accessed 20 Oct 2016.

Meyburg B, Haraszthy L, Meyburg C, Viszlo I. Satellite and ground tracking of a young Imperial Eagle Aquila heliaca: break-up of the family and dispersal. Voge. 1995:116:153-7.

Minton C, Gosbell K, Johns P, Christie M, Fox JW, Afanasyev V. Initial results from light level geolocator trials on Ruddy Turnstone Arenaria interpres reveal unexpected migration route. Wader Study Group Bull. 2010;117:9-14.

Qian F, Wu H, Gao L, Zhang H, Li F, Zhong X, Yang X, Zheng G. Migration routes and stopover sites of Black-necked Cranes determined by satellite tracking. J Field Ornithol. 2009;80:19-26.

Robert E, Lee T, David C, Colleen M, Daniel M, Jon C, Nils W, Brian J, Philip $F$, Theunis $P$. Extreme endurance flights by landbirds crossing the Pacific Ocean: ecological corridor rather than barrier? Proc R Soc B. 2009;276:447-57.

Xu C, Guo Y, Zhao W. Behavior time budget and daily rhythm of Hooded Crane (Grus monacha) in breeding season at foraging site. Chin J Appl Environ Biol. 2006;12:533-6.
Zhang B, Wang J, Liu Q, Tian X. Habitat quality evaluation of Hooded Crane in Dazhanhe Nature Reserve of Heilongjiang Province, China. J Northeast For Univ. 2011:39:92-4 (in Chinese).

Zhao F, Zhou L, Xu W, Zhao F, Zhou L, Xu W. Habitat utilization and resource partitioning of wintering Hooded Cranes and three goose species at Shengjin Lake. Chin Birds. 2013;4:281-90.

Zhao Y, Ma Z, Chen J. Food habits of Hooded Crane (Grus monacha) in winter at the east Tidelands of Chongming Island. J Fudan Univ. 2002;41:609-13 (in Chinese).

Zheng Z. Main achievements of crane research in China. Chin J Wildl. 1987;2:3-5 (in Chinese).

Zhou B, Zhou L, Chen J, Cheng Y, Xu W. Diurnal time-activity budgets of wintering Hooded Cranes (Grus monacha) in Shengjin Lake China. Waterbirds. 2016a;33:110-5.

Zhou H, Na X, Zang S. Dynamic change of red-crowned crane habitat suitability in the west Songnen Plain during the past 30 years. Chin J Ecol. 2016b;35:1009-18 (in Chinese)

Zou H, Huang H, Song Y, Wu Q. Research progress on cranes in Songnen Plain, China. Chin J Wildl. 2018;39:433-7 (in Chinese).
Ready to submit your research? Choose BMC and benefit from:

- fast, convenient online submission

- thorough peer review by experienced researchers in your field

- rapid publication on acceptance

- support for research data, including large and complex data types

- gold Open Access which fosters wider collaboration and increased citations

- maximum visibility for your research: over $100 \mathrm{M}$ website views per year

At $\mathrm{BMC}$, research is always in progress.

Learn more biomedcentral.com/submissions 